\title{
Never too early to examine the evidence!
}

On a bright day in Philadelphia just over one year ago, a group of surgeons met to discuss the possibility of critically examining the literature published thus far on endoscopic techniques in the management of sinonasal and skull base tumours at the instigation of the European Rhinologic Society. Whilst it has proved relatively easy to provide level 1 evidence for virtually all medical treatments of allergic rhinitis ${ }^{(1)}$, even for many therapies in rhinosinusitis ${ }^{(2)}$, in rhinology in general we have struggled with surgical approaches, not because they don't work but because they do not readily lend themselves to placeboarms or drug-company sponsorship. The rapid uptake of endoscopic techniques for nose and sinus diseases relied on more than just the undoubted enjoyment of using the instrumentation and whilst we had witnessed the escalation and extension of the techniques to the skull base and sino-orbital interface for benign conditions, there was a natural hesitation and concern about applying these to tumours and especially to malignant disease ${ }^{(3)}$.

The application of endonasal endoscopic approaches for many benign tumours has now become well-established and the literature contains many large long-term cohorts for inverted papillomas, angiofibromas and benign fibro-osseous lesions amongst others ${ }^{(4-9)}$. The pituitary was also an area which attracted the attentions of endoscopic surgeons at a relatively early stage and fostered a multi-disciplinary approach ${ }^{(10-12)}$. However, a comprehensive review of all this evidence, albeit level 3 and 4, has been hitherto lacking.

The situation with malignant lesions is more contentious as not only are these tumours rare, but they often present late with advanced disease. The advent of craniofacial resection ${ }^{(13,14)}$ and newer medical oncological approaches ${ }^{(15)}$ have significantly improved survival for many patients but these treatments may come at a price. With careful patient selection it is clear that a number of patients can undergo effectively the same excision via an entirely endonasal endoscopic approach with potentially reduced morbidity ${ }^{(16-22)}$. However, extending endoscopic surgery well beyond the nose and sinuses also risks catastrophic complications which require specific solutions $(23,24)$ and crosses speciality frontiers with the potential for 'turfwars'. Notwithstanding this, around the world and particularly in Europe, there are an increasing number of surgeons, usually working in teams, able and willing to push things forwards for the benefit of patients, both adults and children ${ }^{(25)}$. This has generated significant collaboration and cross-fertilisation, leading to the call by some for a new speciality of rhino-neurosurgery. This embodies the concept of 'two-way traffic' with lesions that arise intracranially also being considered for endonasal approaches ${ }^{(26)}$ as well as resection of rhinologic tumours that have extended above and beyond the skull base.

However, it should be emphasized that we are not talking about 'debulking' tumours but undertaking a truly oncologic resection. It is not occasional surgery done once a year and must be underpinned by expertise in imaging and histopathology, a personal understanding of the unique natural histories exhibited by these tumours and the surgical expertise that encompasses both endoscopic and external techniques for neoplasia. The importance of a multidisciplinary approach, adherence to oncologic principles with intent to cure and the need for long-term follow-up are fundamental, particularly for tumours which can recur decades later.

To do this as well as possible, we need to critically examine what has already been done, to highlight future needs and because of the rarity of the individual tumours, to accurately and prospectively collect data. The result of these deliberations is the supplement which accompanies this issue of the journal, the European Position Paper on Endoscopic Management of Tumours of the Nose, Paranasal Sinuses and Skull Base ${ }^{(27)}$, which will be launched at the ERS/ISIAN meeting in Geneva in June of this year. It has been an extremely interesting exercise, involving over 40 clinicians from 15 countries with farranging expertise in many disciplines including otorhinolaryngology, head and neck, neurosurgery, medical oncology, imaging and histopathology. I am extremely grateful to them, all for their enthusiastic support of the project and in particular I would like to recognize the pivotal role of my co-chairs, Professors Stammberger, Nicolai and Castelnuovo.

As always it has raised as many questions as it answers but it is never too early to examine the evidence as only by doing this will we see where we need to go and how we might achieve it.

\section{REFERENCES}

1. Bousquet J, van Cauwenberge P, Khaltaev N, et al. ARIA Workshop Group. Allergic rhinitis and its impact on asthma. J Allergy Clin Immunol 2001; 108 (Suppl 5): 1-333.

2. Fokkens W, Lund V, Mullol J, European Position Paper on Rhinosinusitis and Nasal Polyps group. European position paper on rhinosinusitis and nasal polyps 2007. Rhinology 2007; Supplement 20: 1-136.

3. Fokkens W. The endoscope: new opportunities requiring new skills. Rhinology 2009, 47: 337-338.

4. Hofmann T, Bernal-Sprekelsen M, Koele W, Reittner P, Klein E, Stammberger H. Endoscopic resection of juvenile angiofibromas-long term results. Rhinology 2005; 43: 282-289.

5. Mirza S, Bradley PJ, Acharya A, Stacey M, Jones NS. Sinonasal inverted papillomas: recurrence, and synchronous and metachronous malignancy. J Laryngol Otol 2007; 121: 857-864. 
6. Heathcote K, Nair S. The impact of modern techniques on the recurrence rate of inverted papilloma treated by endonasal surgery. Rhinology 2009; 47: 339-344.

7. Carrau RL, Snyderman CH, Kassam AB, Jungreis CA. Endoscopic and endoscopic-assisted surgery for juvenile angiofibroma. Laryngoscope 2001; 111: 483-487.

8. Schick B, Steigerwald C, el Rahman T, Draf W. The role of endonasal surgery in the management of frontoethmoidal osteomas. Rhinology 2001; 39: 66-70.

9. Bignami M, Dallan I, Terranova P, Battaglia P, Miceli S, Castelnuovo P. Frontal sinus osteomas: the window of endonasal endoscopic approach. Rhinology 2007; 45: 315-320.

10. Jho HD, Carrau RL, Ko Y, Daly MA. Endoscopic pituitary surgery: an early experience. Surgical Neurol 1997; 47: 213-223.

11. Cappabianca P, Alfieri A, de Divitiis E. Endoscopic endonasal transsphenoidal approach to the sella: towards functional endoscopic pituitary surgery (FEPS). Minim Invasive Neurosurg. 1998; 41: 66-73.

12. Castelnuovo P, Pistochini A, Locatelli D. Different surgical approaches to the sellar region: focusing on the "two nostrils four hands technique". Rhinology 2006; 44: 2-7.

13. Dulguerov P, Allal AS, Calcaterra TC. Esthesioneuroblastoma: a meta-analysis and review. Lancet Oncology 2001; 2: 683-690.

14. Howard DJ, Lund VJ, Wei WI. Craniofacial resection for tumors of the nasal cavity and paranasal sinuses: a 25 -year experience. Head Neck 2006; 28: 867-873.

15. Guntinas-Lichius O, Kreppel MP, Stuetzer H, Semrau R, Eckel HE, Mueller RP. Single modality and multimodality treatment of nasal and paranasal sinuses cancer: a single institution experience of 229 patients. Eur J Surg Oncol. 2007; 33: 222-228.

16. Goffart Y, Jorissen M, Daele J, et al. Minimally invasive endoscopic management of malignant sinonasal tumours. Acta OtoRhino-Laryngologica Belgica 2000; 54: 221-232.

17. Carrau R, Kassam A, Snyderman C, Horowitz M. Resection of olfactory neuroblastoma by a transnasal endoscopic approach. Skull Base: An Interdisciplinary Approach 2005; 15 (Suppl 1): 31.

18. Unger F, Haselsberger K, Walch C, Stammberger H, Papaefthymiou G. Combined endoscopic surgery and radiosurgery as treatment modality for olfactory neuroblastoma (esthesioneuroblastoma). Acta Neurochirurgica 2005; 147: 595-602.

19. Castelnuovo PG, Belli E, Bignami M, Battaglia P, Sberze F, Tomei G. Endoscopic nasal and anterior craniotomy resection for malignant nasoethmoid tumors involving the anterior skull base. Skull Base: An Interdisciplinary Approach 2006; 16: 15-18.

20. Lund V, Howard DJ, Wei WI. Endoscopic resection of malignant tumors of the nose and sinuses. Am J Rhinology 2007; 21: 89-94.
21. Nicolai P, Battaglia P, Bignami M, et al. Endoscopic surgery for malignant tumours of the sinonasal tract and adjacent skull base: a 10 year experience. Am J Rhinology 2008; 22: 308-316.

22. Jardeleza C, Seiberling K, Floreani S, Wormald PJ. Surgical outcomes of endoscopic management of adenocarcinoma of the sinonasal cavity. Rhinology 2009; 47: 354-361.

23. Hadad G, Bassagasteguy L, Carrau RL, et al. A novel reconstructive technique after endoscopic expanded endonasal approaches: vascular pedicle nasoseptal flap. Laryngoscope 2006; 116: 18821886.

24. Kassam A, Snyderman CH, Carrau RL, Gardner P, Mintz A. Endoneurosurgical hemostasis techniques: lessons learned from 400 cases. Neurosurg Focus 2005; 19: E7.

25. Locatelli D, Rampa F, Acchiardi I, Bignami M, Pistochini A, Castelnuovo P. Endoscopic endonasal approaches to anterior skull base defects in pediatric patients. Childs Nerv Syst 2006; 22: 14111418.

26. Gardner PA, Kassam AB, Snyderman CH, et al. Outcomes following endoscopic, expanded endonasal resection of suprasellar craniopharyngiomas: a case series. J Neurosurg 2008; 109: 6-16.

27. Lund VJ, Stammberger H, Nicolai P, Castelnuovo P. European Position Paper on Endoscopic Management of Tumours of the Nose, Paranasal Sinuses and Skull Base. Rhinology 2010; Supplement 22: 1-143.

Valerie J. Lund

Editor in Chief

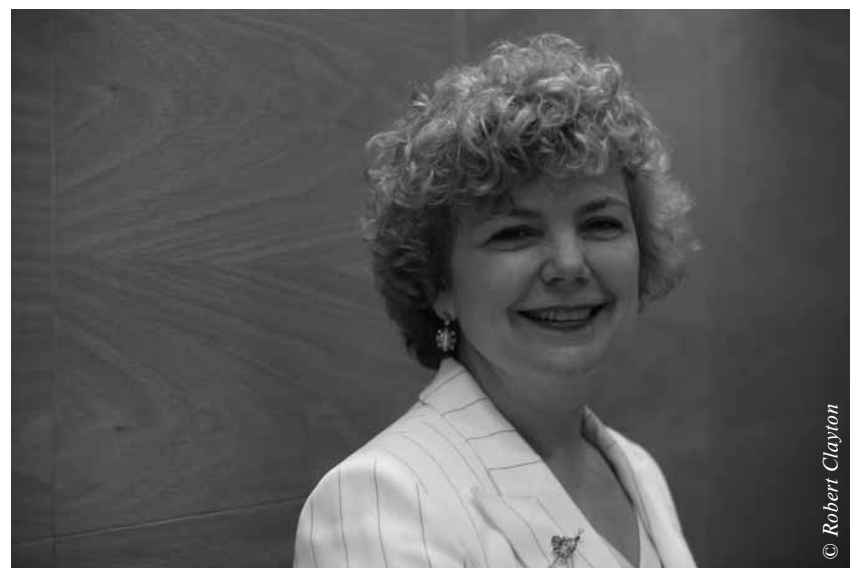

